\title{
CONDIÇÕES DE TRABALHO E ENFERMAGEM: A TRANSVERSALIDADE DO SOFRIMENTO NO COTIDIANO ${ }^{1}$
}

\author{
CONDITIONS OF WORK AND NURSING: THE TRANSVERSENESS OF THE SUFFERING IN THE DAILY LIFE.
}

CONDICIONES DE TRABAJO Y ENFERMERÍA: LA TRANVERSALIDAD DEL SUFRIMIENTO EN EL COTIDIANO

\section{Soraya Maria de Medeiros ${ }^{2}$, Laiane Medeiros Ribeiro ${ }^{3}$, Sandra Michelle Bessa de Andrade Fernandes ${ }^{4}$, Verônica Simone Dutra Veras ${ }^{5}$}

RESUMO: Trata-se de um desdobramento de um projeto de dissertação de mestrado, que teve como objetivo analisar o sofrimento dos trabalhadores de enfermagem em função do aumento da jornada de trabalho, do multiemprego e/ou das escalas extras de trabalho e das condições de trabalho no cotidiano desses trabalhadores em um hospital público de Natal/RN. A metodologia foi pautada em um estudo descritivo com abordagem qualitativa. Utilizou-se como técnica de coleta de informações a entrevista individual guiada por um roteiro com questões abertas e semi-estruturadas. O período correspondeu aos meses de julho e agosto de 2003. Na análise dos dados, as entrevistas transcritas foram organizadas de acordo com o grupo a que pertencia, foi realizada uma leitura exaustiva dos textos para o agrupamento de informações com características comuns. Cada unidade de registro foi sendo agrupada de acordo com categorias empíricas que surgiram durante o processo. A análise das informações foi realizada com base em elementos do método dialético. Os resultados encontrados apontam para a existência de um sentimento de vazio e fragilização dos laços afetivos com familiares; conflitos de valores referentes à relação ser/ter; vivência de ansiedade e estresse pelo sentimento de impotência vivenciado no cotidiano de trabalho; o sentimento de aprisionamento e perda dos sonhos decorrente do acúmulo de jornadas de trabalho; reconhecimento da transversalidade do sofrimento sob a ótica de gênero. Conclui-se portanto que o aumento da jornada de trabalho está trazendo aos trabalhadores desgaste físico, emocional e sofrimento no cotidiano somandose à precariedade das condições de trabalho, gerando insatisfação do trabalhador, comprometendo a assistência prestada, assim como, dificultando as relações interpessoais no âmbito das dimensões públicas e privadas da vida cotidiana.

PALAVRAS-CHAVE: Condições de trabalho; Enfermagem; Jornada de trabalho.

SUMMARY: This paper discuss about a master's thesis academicals work. It had as objective to analyze the suffering of nursing workers through the increase of the working hours, of the multi work or the extra scales of work, of the laboring conditions in these workers' daily lives. The research was developed in a public hospital in Natal/RN. The methodology was led by a descriptive study with a qualitative approach. The technique of information collecting was employed. The individual interviews were guided by a script with open and halfstructuralized questions. The period of information collecting corresponds to the months of July and August of 2003. In the analysis of data, the transcribed interviews were organized according to the group it belonged, an exhaustive reading of the texts was realized for the grouping of informations with common characteristics. Each unity of register was being grouped according to empiric categories that arose during the process. The analysis of informations was realized based in elements of the dialectic method. The results of the research lead to: the existence of an emptiness feeling and imbrutement of the affective bows with relatives; conflicts of values concerning the relation of being/having; anxiety and stress caused by impotence feelings in daily work; the feeling of dreams capture and loss as result of the working hours accumulation; recognition of the suffering through a transversal line under the sort optics. It is concluded therefore that the increase of the working hours is bringing to the workers physical and emotional consuming, and the suffering in the daily life is a result of the precariousness of the work conditions. All these factors are generating unsatisfied workers, compromising the given assistance, as well as making it difficult the interpersonal relations into the public and private dimensions of the daily life.

KEY WORDS: Working Conditions; Nursing; Work hours.

\footnotetext{
${ }^{1}$ Projeto de pesquisa, parte da Dissertação "Aumento da jornada de trabalho: qual a repercussão na vida dos trabalhadores da enfermagem? Autora: VERAS, Simone Dutra.

${ }^{2}$ Enfermeira, Doutora em enfermagem pela EERP/USP.

Coordenadora do Programa de Pós-graduação em Enfermagem da Universidade Federal do Rio Grande do Norte e orientadora da pesquisa. Natal/RN

${ }^{3}$ Enfermeira, Mestranda do Programa de Pós-graduação em Enfermagem da Universidade Federal do Rio Grande do Norte, exbolsista PIBIC e bolsista CNPq. Natal/RN.

${ }^{4}$ Enfermeira, Mestre em Enfermagem pelo Programa de Pósgraduação em Enfermagem da Universidade Federal do Rio Grande do Norte. Natal/RN.

${ }^{5}$ Enfermeira, Mestre em Enfermagem pelo Programa de Pósgraduação em Enfermagem da Universidade Federal do Rio Grande do Norte. Natal/RN
} 
RESUMEN: Este estudio es un desdoblamiento de un proyecto de maestría que tuvo como objetivo analizar el sufrimiento de los trabajadores de enfermería en función del aumento de las horas de trabajo, del multiempleo e/ou de la escala-extra de turno y las condiciones de trabajo en el cotidiano de eses trabajadores en un hospital publico de la cuidad de Natal / RN. La metodología fue pautada en un estudio descriptivo con abordaje cualitativa, en el cual fue adoptada como técnica de recolección de la información, la entrevista individual guiada por un cuestionario con preguntas abiertas y semiestructuradas. El período fue correspondiente a los meses de julio e agosto de 2003. En la analice de las informaciones, las entrevistas transcriptas fueron organizadas de acuerdo con el grupo a que pertenecía, fue realizada una lectura exhaustiva de los textos para el agrupamiento de informaciones con características comunes. Cada unidad de registro fue siendo agrupada de acuerdo con categorías empíricas que surgirán durante el proceso. La analice de las informaciones fue realizada con base en

\section{INTRODUÇÃO}

O presente estudo consiste em um desdobramento de um projeto de dissertação de mestrado, no qual a bolsista de PIBIC foi inserida, tendo sido responsável por um aspecto da investigação, com um enfoque especificamente destinado para o seu estudo.

Esse enfoque corresponde a um olhar sobre o sofrimento psíquico no trabalho dos profissionais de saúde, mais especificamente, a enfermagem, e que conseqüências poderá acarretar no seu cotidiano, decorrente do aumento da jornada de trabalho, das escalas de plantão e da complexidade das condições de trabalho, em seu contexto no mundo do trabalho atual.

O interesse em estudar o sofrimento psíquico surgiu a partir da experiência prática de uma das autoras do presente estudo. Vivência na qual foi possível constatar as condições inadequadas de trabalho nas quais se encontram inseridos os profissionais de enfermagem, assim como da reflexão sobre as perspectivas futuras de inserção nesse mercado de trabalho precarizado. Os profissionais dessa área correspondem a maior parcela da força de trabalho em saúde, com a singularidade de serem majoritariamente do sexo feminino. Essa singularidade se traduz na prática por um perfil humano genérico de múltiplas funções, como: trabalhadoras da saúde, mães e donas de casa, entre outros.

Os trabalhadores dos serviços públicos, inseridos em um contexto sócio-econômico neoliberal, vêm paulatinamente sofrendo as conseqüências da redução do seu poder aquisitivo. As saídas buscadas pela grande maioria dos servidores públicos no setor elementos del método dialéctico. Los resultados encontrados apuntan para: la existencia de un sentimiento de vacío y fragilidad de los lazos afectivos con sus familiares; conflictos de valores referentes a relación ser/tener; vivencia de ansiedad y estrés por el sentimiento de impotencia vivenciado en el cotidiano de trabajo; el sentimiento de opresión y pierda de los sueños decurrentes de la acumulación de horas de trabajo; reconocimiento de la presencia del sufrimiento referente a la óptica del genero. Se concluye que el aumento de las horas de trabajo está ocasionando a los trabajadores desgaste físico, emocional y sufrimiento en el cotidiano. Estos factores se asoman a las precarias condiciones de trabajo, generando insatisfacción del trabajador, comprometiendo la asistencia prestada, dificultando las relaciones interpersonales en el ámbito de las dimensiones públicas y privadas de la vida cotidiana.

PALABRAS CLAVE: Condiciones de trabajo; Enfermería; Horas de trabajo.

da saúde, sobretudo na enfermagem, tem sido a adoção de outros vínculos empregatícios, realidade essa que pode ser constatada em instituições públicas e privadas. ELIAS \& NAVARRO (2006) corroboram afirmando que a insegurança gerada pelo desemprego faz com que os trabalhadores se submetam a regimes e contratos de trabalho precários. Especificamente no caso dos profissionais de enfermagem, por desenvolverem as suas atividades em escalas de plantão, constata-se a existência de uma facilitação na conciliação das escalas, podendo o mesmo acumular duas ou até três escalas de trabalho. Comprova-se que todas as formas adotadas por esses trabalhadores, para a complementação da sua renda - mediante a falta de perspectiva de valorização salarial - resultam no aumento da jornada de trabalho. Ao ingressar no serviço público, na maioria dos casos, os servidores assumem uma jornada de trabalho de 40 horas semanais ou 144 horas mensais, porém, com o multiemprego e/ou escalas extras, as horas efetivamente trabalhadas podem chegar a 80 ou até 120 horas semanais (VERAS, 2003).

Embora se constate a existência do multiemprego em todos os níveis assistenciais do setor da saúde, especificamente na enfermagem, é importante ressaltar os efeitos da acumulação de escalas de serviço e o conseqüente aumento da jornada de trabalho. Esses fatores somam-se às características tensiógenas dos serviços hospitalares, tanto pela natureza do cuidado prestado às pessoas em situações de risco como pela divisão social do trabalho e hierarquia presentes na equipe de saúde. SENTONE \& GONÇALVES (2002) relatam que o sofrimento psíquico é uma questão primordial, uma vez que o profissional lida frequentemente com a dor 
e o sofrimento do outro. Além disso, podem existir situações em que o conteúdo do trabalho não lhe são favoráveis, o que eleva o risco de agravar a saúde deste trabalhador.

Constata-se atualmente nos trabalhadores do serviço público uma frustração pela falta de material, o que exige uma maior capacidade de improvisação desses trabalhadores para a realização de procedimento, deixando-os insatisfeitos em relação à assistência prestada ao paciente. Esses elementos somados podem desencadear o sofrimento no cotidiano desses trabalhadores.

Segundo DEJOURS (1992, p.10), o sofrimento representa

"um estado de luta do sujeito contra forças que o estão empurrando em direção à doença mental", ou seja, "quando a organização do trabalho entra em conflito com o funcionamento psíquico dos homens, quando estão bloqueadas todas as possibilidades de adaptação entre a organização do trabalho e o desejo dos sujeitos, então emerge um sofrimento patogênico".

DEJOURS (1992), ao discorrer sobre as condições materiais no trabalho, afirma que nas tarefas ditas de execução, o trabalhador se vê de algum modo impedido de fazer corretamente seu trabalho, constrangido por métodos e regulamentos incompatíveis entre si. Essa precariedade das condições de trabalho, somadas à dificuldade de convivência com os colegas de profissão, acarretam prejuízos na vida cotidiana privada desse trabalhador, tendo em vista que pela permanência no hospital, devido às escalas extras de plantões, esses trabalhadores se vêem forçados a abdicar do seu lazer em prol de melhores condições salariais, mas, para isso, sacrificam parte do tempo dedicado à convivência familiar, o que gera um sentimento de vazio e fragilização dos laços afetivos.

Ressalta-se que esse sofrimento aumenta proporcionalmente ao esforço exercido pelo trabalhador, na medida em que não se pode satisfazer as expectativas criadas no plano material, afetivo, social e político. Trabalhar, segundo DEJOURS (2001), é não apenas exercer atividades produtivas, mas também conviver. Assim, uma organização do trabalho racional deve antes de tudo preocupar-se com a eficácia técnica, mas deve também incorporar argumentos relativos à convivência, ao viver em comum, às regras de sociabilidade, ou seja, ao mundo social do trabalho, bem como argumentos relativos à proteção do ego e à realização do ego, ou seja, à saúde e ao mundo subjetivo.

Segundo PITTA (1994), ao estabelecer uma relação entre organização do trabalho, carga mental e sofrimento psíquico, assinala que a evolução da tecnologia para uma série de trabalhos, inclusive o trabalho hospitalar, tem se revestido de componentes cognitivos complexos e muitas vezes sobrecargas mentais nos trabalhadores. Essa autora afirma também que a organização do trabalho atua na gênese do sofrimento psíquico através de alguns elementos facilmente identificáveis, quais sejam: as jornadas prolongadas de trabalho, os ritmos acelerados de produção, a pressão claramente repressora e autoritária instalada numa hierarquia rígida e vertical, a inexistência ou exigüidade de pausas para descanso ao longo das jornadas de trabalho, a alienação de trabalho e do trabalhador, a fragmentação de tarefas e a desqualificação do trabalho realizado e, por conseguinte, de quem o realiza. PITTA (1994) afirma ainda que a noção do sofrimento psíquico designa esta difusa zona entre a saúde e a doença, significando um conceito mais preciso no âmbito da Psicopatologia do Trabalho.

Considerando toda essa problemática, é relevante fazer os seguintes questionamentos: Qual a repercussão desse sofrimento no cotidiano da vida dos trabalhadores da enfermagem dentro e fora do trabalho? De que forma as condições de trabalho influenciam no sofrimento desses trabalhadores? Como os trabalhadores de enfermagem se vêem nesse processo?

\section{OBJETIVOS}

\section{Objetivo geral}

Analisar o sofrimento no cotidiano dos trabalhadores de enfermagem submetidos a um aumento da jornada de trabalho, ao multiemprego e/ou a escalas extras de trabalho, em um hospital Público de Natal/RN.

\section{Objetivos específicos}

Descrever a repercussão das condições de trabalho na vida cotidiana desses trabalhadores, sob o enfoque do sofrimento.

Identificar de que forma as condições de trabalho influenciam no sofrimento desses trabalhadores.

Identificar as concepções dos trabalhadores sobre suas condições de trabalho e a transversalidade do sofrimento no seu cotidiano a partir das falas desses atores.

\section{METODOLOGIA}

\section{Tipo de estudo}

Pesquisa do tipo descritivo-exploratória com abordagem qualitativa. Segundo GRESSLER (2003), a pesquisa descritiva é usada para descrever fenômenos existentes, situações presentes e eventos, identificar problemas e justificar condições, comparar e avaliar o que os outros estão desenvolvendo em situações para futuros planos e decisões. Acerca da investigação qualitativa, MINAYO (1998) afirma que ela requer como atitudes fundamentais a abertura, a 
flexibilidade, a capacidade de observação e de interação entre o grupo de investigadores e os atores sociais envolvidos. Seus instrumentos costumam ser facilmente corrigidos e readaptados durante o processo de trabalho de campo, visando o alcance dos objetivos da investigação.

\section{Caracterizando o local da pesquisa}

O presente estudo desenvolveu-se em um hospital estadual de referência para todo o Estado, integrante do Sistema único de Saúde-SUS. Essa instituição está subordinada à administração da Secretaria Estadual de Saúde (SESAP) e disponibiliza o acesso universal para usuários em todas as faixas etárias.

O hospital dispõe de 1525 funcionários efetivos. Na enfermagem, são 672 profissionais, dos quais 74 são enfermeiros e 598 são auxiliares e técnicos de enfermagem. Embora o hospital não disponha de informação precisa, sabe-se que parte dos auxiliares de enfermagem são contratados como auxiliares de serviços gerais (ASG), isto é, como nível elementar, apesar de terem sido submetidos a um processo de qualificação, o qual se constitui em cursos de auxiliares e técnicos de enfermagem.

Os sujeitos entrevistados foram aglutinados em grupos e codificados de acordo com a função que exercem no trabalho: "Grupo E" para enfermeiros; "Grupo AT" para auxiliares e técnicos de enfermagem e "Grupo G" para gestores. Cada entrevistado recebeu uma numeração de acordo com a seqüência das entrevistas. MINAYO (2004) afirma que na escolha da amostragem qualitativa deve-se privilegiar os sujeitos sociais que detêm os atributos que o investigador pretende conhecer; que o grupo estudado deve ser em número suficiente para permitir uma reincidência das informações e ao mesmo tempo não deve descartar as informações diferenciadas da maioria. Esse grupo deve ser diversificado para permitir captar semelhanças e diferenças nas informações.

Os critérios utilizados para a definição dos grupos tiveram como base: a inserção de cada um na divisão social do trabalho e a representação dos mesmos no contexto abordado, visando captar as várias visões sobre o tema.

Especificamente sobre os grupos E e AT, utilizou-se, para a escolha dos entrevistados, a inserção destes em uma jornada de trabalho superior a 40 horas semanais definidas pelo vínculo com a SESAP, seja pelo multiemprego ou pelas múltiplas escalas de plantão no hospital em estudo. A escolha dos entrevistados, dentro do critério de inclusão estabelecido, partiu da disponibilidade dos entrevistados de concederem as entrevistas.

O total de entrevistados foi: dez enfermeiros, onze técnicos, oito auxiliares e quatro gestores.

A forma de coleta das informações foi realizada através da entrevista com roteiro semiestruturado, gravada, com consentimento informado, segundo parecer 196/96 do Conselho Nacional de Saúde. Ressalta-se que o projeto foi submetido à apreciação pelo Comitê de Ética e Pesquisa da UFRN.

Para complementação de informações e contribuição para as análises, foi elaborado um diário de campo, com as impressões dos pesquisadores sobre a estrutura física, as expressões não verbais dos entrevistados no momento das entrevistas, das observações do ambiente e seus atores no contexto geral, no campo pesquisado. A análise das informações foi realizada a partir das categorias: sofrimento em DEJOURS $(1992,2001)$ e cotidiano em HELLER (2000). Na análise dos dados, as entrevistas transcritas foram organizadas de acordo com o grupo a que pertencia, foi realizada uma leitura exaustiva dos textos para o agrupamento de informações com características comuns. Cada unidade de registro foi sendo agrupada de acordo com categorias empíricas que surgiram durante o processo. A análise das informações foi realizada com base em elementos do método dialético, objetivando-se buscar a compreensão da realidade estudada. Ao falar do método baseado na dialética, MINAYO (1998, p.86) afirma que tem por base a observação da realidade social e sua adequação à visão dialética que privilegia "a contradição e o conflito predominando sobre a harmonia e o consenso; o fenômeno da transição, da mudança, do vir-a-ser sobre a estabilidade; o movimento histórico; a totalidade e a unidade dos contrários".

As categorias de análise foram criadas mediante o recorte de entrevistas com características comuns, onde foi submetido à leitura transversal e recortadas as unidades de registro constituídos por frases, orações ou expressões significativas. Cada unidade de registro foi sendo agrupada a partir das categorias: sofrimento em DEJOURS $(1992,2001)$ e cotidiano em HELLER (2000).

\section{RESULTADOS}

A análise dos dados permitiu a definição das categorias: Trabalho e vida cotidiana e Transversalidade do sofrimento no cotidiano, sendo que nessa ultima emergiu uma subcategoria: as condições de trabalho.

\section{Trabalho e vida cotidiana}

A história da realização do ser social, muitos já o disseram, objetiva-se através da produção e reprodução da sua existência, ato social que se efetiva pelo trabalho. É a partir do trabalho, em sua cotidianidade, que o homem torna-se ser social, distinguindo-se de todas as formas não humanas (ANTUNES, 2003a).

HELLER (1991) afirma que em função da centralidade do trabalho na vida cotidiana, o tempo é definido a partir deste, estando as demais atividades na dependência do tempo de trabalho. Neste sentido, 
tempo de trabalho e tempo livre são transversais para o conhecimento da cotidianidade dos trabalhadores em estudo.

Esse tempo dedicado ao trabalho afeta diretamente a vida pessoal dos trabalhadores como evidencia A6 e E10:

[...] na (vida) pessoal tem influência, porque a gente não consegue ter um relacionamento direito, entendeu? Não consegue assim, cuidar da mãe, por exemplo, não consegue direito, a gente não consegue ter um animal de estimação, porque sabe que não vai ter tempo pra ele, entendeu? É assim a vida corrida. (A6)

"Ah... influencia demais, você não ter lazer, é horrível! muitas vezes eu passo mais de seis meses sem ir ao centro da cidade, sem entrar numa loja. De casa pro trabalho... do trabalho pra casa. Às vezes eu to aqui dentro, vejo na janela o sol e queria ta lá fora, mas nem dá. Aí fico só olhando o sol da janela... querendo ir ao shopping, passear, andar, essas coisas... eu passo tanto tempo sem ir que quando vou acho estranho... de tanto trabalho, se eu não fizer isso não vou conseguir". (E10)

OLIVEIRA (2003) acrescenta que a sociedade sobrecarregada de trabalho cria contradições para si mesma, na medida em que seus objetivos acabam se tornando conflitivos. A ênfase exagerada na vida profissional, em detrimento da vida privada, acaba voltando-se contra a própria sociedade, na proporção que, deixando em segundo plano a função educativa dos pais, abre espaço à deriva no destino de muitas crianças e jovens.

Acerca da ausência na educação dos filhos, da vida íntima, das oportunidades de convivência, T13 e E4

relatam:

"É você não tem tempo pros meninos. Quando você chega os meninos já estão grandes, já tão enormes. Aí você diz assim: já está um rapaz(risos). Quem é esse homem aí dentro de casa. É os seus filhos que cresceu e você não teve tempo nem pra ver o desenvolvimento do rapaz. E... outras coisas, a vida sexual também, influencia muito. Você está cansado. Você pode até.... chegar a uma disfunção erétil. Já aconteceu comigo. Estou sendo tratado já. Você pode é... mil e uma coisas. Até mesmo no relacionamento a dois, a convivência com os filhos, sua esposa, não é? Porque você não vê, você vai pra casa pra descanso: porque sua casa não é um lar, é apenas um local de descanso. Geralmente você vive mais no local de trabalho do que na sua própria casa. Então isso influencia muito, influencia demais".

[...] outro dia eu cheguei em casa e falei assim: "nem dá um abraço em mainha?" "Ah, mãe eu já estou tão acostumada com você fora..." aí faz a gente refletir, até que ponto... você trabalha tanto para ter qualidade de vida, que qualidade de vida é essa não é? só as coisas materiais? E a parte sentimental? e a parte do relacionamento? e o ser? O ser da minha filha, o ser da minha família, o ser do meu marido, o meu ser, está se transformando e eu só quero ter, ter e ter (E4).

O aumento do tempo dedicado ao trabalho decorrente do aumento da jornada de trabalho vem levando à redução do tempo de convivência familiar, sendo um fator de angústia, como deixam claras as falas dos entrevistados. Observa-se que tanto as mulheres quanto os homens manifestam esta preocupação, sobretudo com relação aos filhos. SARTI (1997) concorda ao afirmar que a centralidade que 0 trabalho assume na vida cotidiana dos indivíduos diminui a disponibilidade, tanto do homem quanto da mulher, para a vida familiar, inclusive no que concerne à sua relação com os filhos.

HELLER (2000) evidencia que o que o ser humano deseja da vida cotidiana é que ela lhe permita o mínimo de esforços para que esteja enquadrado na reprodução social. O menor deles seria identificar-se com as necessidades normais dos indivíduos. Diante da carga horária excessiva de trabalho, os trabalhadores da enfermagem não usufruem desse menor esforço para ter uma vida de lazer, de convívio social, de integração familiar. Até a própria relação entre os parceiros no casamento torna-se prejudicada, o que pode causar insatisfação e reclamação por parte do parceiro. Como se pode constatar na fala a seguir:
[...] chego em casa cansada, não tenho tempo de... não tenho mais paciência de olhar para o meu marido, quero mais é me deitar e ir dormir. Meu marido reclama. A gente não tem mais vontade de fazer nada quando chega em casa [risos]. É verdade. Só no final de semana, quando eu sei que no outro dia eu não vou trabalhar, não vou dar diurno, então eu tenho vontade de namorar com meu marido, fora isso... não tem vontade porque a gente é tão cansada entende? A gente quer mais é dormir. (T10)

É certo que o trabalho pode ser um espaço privilegiado de realização pessoal, e se assim não fosse as mulheres não teriam lutado tanto para romper as fronteiras dos territórios domésticos e ganhar o direito à realização profissional (OLIVEIRA, 2003). Mas o que acontece é que o trabalho está se tornando o centro da vida de uma forma dominante, o que dificulta uma conciliação com as demais 
dimensões da vida e suas respectivas atividades. Como relata E6:

[...] é muito díficil ser enfermeira, você conciliar casa, marido, filho, o seu dia-a-dia, você muitas vezes esquece de você e cuida só do paciente, do cliente, do enfermo e da família, filho, marido, parente, e você esquece muitas vezes de você, então você quase não tem tempo de ir pra um dentista, quase não tem tempo de ir pra uma academia, quase não tem tempo de ir ao médico.

\section{Transversalidade do sofrimento no cotidiano}

ANTUNES (2003b) ainda acrescenta que uma vida cheia de sentido fora do trabalho supõe uma vida dotada de sentido dentro do trabalho. Uma vida desprovida de sentido no trabalho é incompatível com uma vida cheia de sentido fora dele. A dificuldade de produzir sentido no e com o trabalho, por suas difíceis condições, acarreta insatisfação por parte do trabalhador, como refere $\mathrm{A} 9$ :

"Não...honestamente não há satisfação no trabalho! $E$ isso influi muito no desempenho da gente porque como qualquer profissão quando a gente inicia a gente começa cheia de sonhos, às vezes a gente até se envolve com questões assim... da organização do trabalho, questões do sindicato. Mas aí é uma coisa tão rotineira que a gente termina ficando desestimulado. E o sistema... ele é muito complicado... ele oprime você demais".

Essa insatisfação pode levar a formas de sofrimento psíquicos. O sofrimento aumenta porque os trabalhadores vão perdendo gradualmente a esperança de que a condição que hoje lhes é dada possa amanhã melhorar. Os que trabalham vão cada vez mais se convencendo de que seus esforços, sua dedicação, sua boa vontade, seus sacrifícios pela empresa só acabam por agravar a situação. Assim, entre as pessoas comuns, a relação com o trabalho vai-se dissociando da promessa de felicidade e segurança compartilhadas: para si mesmo, primeiramente, mas também para os colegas, os amigos e os próprios filhos (DEJOURS, 2001).

HELLER (2000) ainda acrescenta que a fé e a confiança desempenham na vida cotidiana um papel muito mais importante que nas demais esferas da vida. O que significa que esses dois sentimentos ocupam um grande espaço na cotidianidade, que sua função mediadora torna-se necessária em maior número de situações. Essas nuances de insatisfações vão conformando formas de sofrimento no cotidiano de trabalho. Essa função mediadora não existindo, configura-se um quadro que, segundo as autoras, é como uma forma de transversalidade do sofrimento consubstanciada no cotidiano de trabalho.

\section{Condições de trabalho}

Somando-se a essa situação, tem-se a precariedade do emprego e da remuneração; a desregulamentação das condições de trabalho em relação às normas legais vigentes ou acordadas e a conseqüente regressão dos direitos sociais. Nos relatos a seguir, pode-se constatar essa situação:

"O que me angustia não é nem a jornada de trabalho, são as péssimas condições de trabalho... e ultimamente eu estou aqui no pronto-socorro aí a gente vê a necessidade real dos pacientes que chegam. A gente não tem maca, não tem um leito, reservado pra ele, quando ele chega". (E9)

"Condições de trabalho eu acho que estão... uma negação! A começar aqui, no hospital, porque a gente aqui não tem condições de trabalho. E ultimamente tem é faltado assim material, como aqui temos a UTI 9 leitos, tem aí 2 leitos desocupados. Temos pacientes precisando de UTI, como tem as cirurgias precisando de um respirador, têm peças quebradas, já foram para conserto e não sabe porque, mas ainda não chegaram aqui, para o tempo que foram! Como tem um paciente agora em cirurgia, e... está dependendo só dessa peça pra colocar aqui no respirador, para ele. E eu acho que a gente da saúde,está muito... pelo pouco tempo que eu tenho, muito desvalorizado!" (A7)

[...] porque a gente trabalha é... numa situação assim, muito crítica. Os hospitais faltam material... vamos dizer não há condição de trabalho, a gente tem que improvisar muitas vezes, não é? $E$ isso é muito ruim...fica difícil. Às vezes você tem que fazer um procedimento, às vezes falta luva, falta gaze. Pronto, hoje mesmo falta lençol.(T5)

No contexto dessa complexidade das condições de trabalho dos entrevistados, o sofrimento se evidencia, pontuado pelo ritmo cotidiano do trabalho. A dimensão da vida pública nesta pesquisa é abordada como a que está relacionada com o mundo do trabalho, a vida profissional do trabalhador, os aspectos da sociabilidade nesse contexto, as formas de educação e intercâmbio técnico-científico e cultural, entre outros. Na dimensão do privado, encontra-se a sua relação com o familiar, a vida do interior do seu mundo doméstico, a relação consigo mesmo e as várias formas de expressão e afetos singulares do exercício da subjetividade.

Nas suas falas, pode-se constatar em relação à dimensão privada e a dimensão pública da vida, os conflitos pelo sentimento de culpa em relação à família, pela falta de tempo de dedicar-se, de acompanhar o desenvolvimento dos filhos, de 
acompanhar os estudos; pelo sentimento de vazio e fragilização dos laços afetivos com familiares; pela dúvida quanto ao certo e errado do ponto de vista dos seus próprios valores, na relação entre ser e ter, na sociedade atual

Segundo ELIAS \& NAVARRO (2006) as mulheres realizam o trabalho não pago e não reconhecido que é o trabalho no lar, o cuidado com os filhos e os familiares doentes, isso gera conflitos e conseqüências importantes para a sua saúde. As relações familiares são prejudicadas pela falta de tempo livre com a família, mas ao mesmo tempo pelo multiemprego, o que gera problemas conflitivos. VASCONCELOS \& PRADO (2004) afirmam que a busca por mais de um emprego são no sentido de ter condições e dar condições de subsistência a sua família. Somados aos conflitos existentes existe o sentimento de aprisionamento e a perda dos sonhos, pelo acúmulo de jornadas de trabalho, pelas horas extras e pelo multiemprego, resultando muitas vezes na supressão de outras formas de sociabilidade e formas de ser no mundo em sua dimensão coletiva e singular, que são tão necessárias à vida do ser humano, tais como, a convivência com a natureza, o autocuidado, o cultivo e a fruição de sonhos e desejos.

GONZÁLES \& BECK (2002) afirmam que pensar a enfermagem significa também pensar nos seus trabalhadores, na concretude do seu cotidiano, no emaranhado de relações da vida pessoal e profissional. SENTONE \& GONÇALVES (2002) ainda acrescentam que sendo o trabalhador responsável pela subsistência da família, se torna um escravo do mundo do consumo, pois o sistema capitalista sugere que o trabalhador digno é aquele que trabalha muito.

\section{CONCLUSÕES}

Considerando que este estudo buscou compreender a relação do sofrimento no cotidiano dos trabalhadores de enfermagem submetidos a um aumento da jornada de trabalho, ao multiemprego e/ou a escalas extras de trabalho, destaca-se alguns aspectos mais relevantes no percurso da pesquisa.

A forma como o trabalho se organiza e o espaço que ocupa na vida cotidiana, vêm retirando a possibilidade dos trabalhadores viverem as múltiplas dimensões da vida que não seja apenas o trabalho. Sob o aspecto da vida cotidiana, ficou evidenciada que a sobrecarga de trabalho interfere nas relações familiares e na vida particular dos trabalhadores da enfermagem em virtude da redução do tempo livre. Em se tratando da força de trabalho feminino, foi verificado que a ampliação do tempo de trabalho não significa a desresponsabilização da mulher frente ao trabalho doméstico. Ao contrário, há a utilização do restrito tempo livre para a realização das tarefas domésticas. As precárias condições de trabalho no serviço público geram também sofrimento, pois o trabalhador se vê impotente em relação a qualidade da assistência ao cliente gerando insatisfação no trabalho e ainda um rompimento no seu processo de trabalho.

As categorias de sofrimento e cotidiano no contexto do mundo do trabalho atual foram descritas e analisadas no processo de apreensão do objeto, à luz do referencial teórico, atingindo os objetivos propostos.

Há que se considerar, entretanto, que a profundidade das discussões e análises suscitadas pela presente pesquisa não se esgotam com esta conclusão, ao contrário, significam muito mais uma abertura de horizontes a descortinar, que significarão novas investigações como desdobramentos das novas indagações.

Considerando os resultados da pesquisa, foi constatado que o sofrimento dos trabalhadores de enfermagem é pontuado pelo ritmo do cotidiano, como tema transversal em todas as dimensões da vida desses trabalhadores, de forma sentida, explicitada ou não através da oralidade; faz parte da sua condição existencial, como signo norteador em sua trajetória: itinerante e transversal, imbricada na própria forma de viver dessas trabalhadoras.

\section{REFERÊNCIAS BIBLIOGRÀFICAS:}

ANTUNES, R. Adeus ao Trabalho? Ensaio sobre as metamorfoses e a centralidade do mundo do trabalho. São Paulo: Cortez; Campinas,SP: Editora da Universidade Estadual de Campinas, 2003a.

ANTUNES, R. Os sentidos do trabalho. São Paulo: Bomtempo, 2003b.

DEJOURS, C. A loucura do trabalho: estudo de psicopatologia do trabalho. São Paulo: Cortez/Oboré, 1992.

DEJOURS, C. A banalização da injustiça social. Rio de Janeiro: Editora FGV, 2001.

ELIAS, M.A.; NAVARRO, V.L. A relação entre o trabalho, a saúde $\mathrm{e}$ as condições de vida: negatividade e positividade no trabalho das profissionais de enfermagem de um hospital escola. Rev Latino-am Enfermagem. v.14,n.4,p.517-25, 2006. GONZALES, R.M.B.; BECK, C.L. O sofrimento e o prazer no cotidiano dos trabalhadores da enfermagem. Texto \& Contexto. v.11,n.1.p.169-186, 2002.

GRESSLER, L A. Introdução à pesquisa. São Paulo: Loyola, 2003.

HELLER, A. O cotidiano e a História. São Paulo: Paz e Terra, 2000.

HELLER, A. Sociología de la vida cotidiana. 3ed. Barcelona: Ediciones Península, 1991.

MINAYO, M C de S. O desafio do conhecimento: pesquisa qualitativa em saúde. São Paulo: Hucitec, 1998.

OLIVEIRA, R D. Reengenharia do tempo. Rio de Janeiro: Rocco, 2003.

PITTA A. Hospital: dor e morte como ofício. 3 ed. São Paulo: Hucitec, 1994. 
SARTI, C.A. Os filhos dos trabalhadores:quem cuida das crinaças? In: OLIVEIRA, E.M.; SCAVONE, L. (org). Trabalho, saúde e gênero na era da globalização. Goiânia:AB, 1997.

SENTONE, A.D.D.; GONÇALVES, A.A.F. Sofrimento no trabalho: significado para o auxiliar de enfermagem com dois vínculos empregatícios. Semina: Ciências Biológicas e da Saúde. v.23, p.3338, 2002.

VASCONCELOS, C.M.C.B.; PRADO, M.L. Vivenciando o sofrimento e os desafios no trabalho: expressões autocríticas de um grupo de enfermeiros educadores. Revista Eletrônica de Enfermagem. [online] 2004. Disponível em: http://www.fen.ufg.br/revista/revista6 1/pdf/f5 desafio s.pdf [Acesso em abril de 2006].

VERAS, V S D. Aumento da Jornada de trabalho: qual a repercussão na vida dos trabalhadores da enfermagem? 2003. 88p. Dissertação (Mestrado) Centro de Ciências da Saúde. Universidade Federal do Rio Grande do Norte, Natal.

Artigo recebido em 21.08.2006

Aprovado para publicação em 31.08.2006 